\title{
Multimodality in medicine: How university medical students approach informative leaflets
}

\section{Begoña Bellés Fortuño}

\section{Universitat Jaume I / IULMA}

\section{bbelles@uji.es}

This study aims to analyse multimodality in medical leaflets to see how images and other semiotic modes combine with text-flow, adding meaning to the message and broadening the communicative spectrum. Traditionally, in the educational sphere, more importance has been given to text rather than to other semiotic modes but, in fact, writing is also a multimodal practice. In medicine, the visual becomes vital, whether accompanied by meaningful written text or not. The present study analyses 50 medical leaflets designed by first year medical students enrolled in their English for Health Sciences module. The leaflets are a very useful activity integrated as part of their spoken project presentations and include a variety of medical topics, i.e. diabetes, Female Genital Mutilation (FGM), Alzheimer's or Huntington's disease, among others. Images were considered in terms of type, structural organization, and size. How images combine with text-flow was also observed. The study is an example of how we can apply multimodality to the teaching and learning of languages in the higher education curriculum, proving that multimodality is not only a theory, but also a field of application.

Key words: Multimodality, Higher Education, English for Medicine, Medicine Studies, Medicine Informative Leaflet (MIL)

\section{Introduction}

In this article, I discuss the opportunities and advantages of using multimodal texts in the English for Medicine classroom at university. I will review the genre of Medicine Informative Leaflets (MILs) as a type of medical informative genre different from drug consumption leaflets or the inpatient discharge instructions. The study of medicines advertising and medicine package leaflets has received more attention than the MIL (DeLorme, Huh, Reid, \& An, 2007; Dickinson, Teather, Gallina \& Newsom-Davis, 2010; Vita Bianco, 2015). In fact, the medicine package leaflet -also called patient information leaflet- has been regulated by the European Commission (2009: 5) through 
a readability guidance which establishes that medicine package leaflets have to be "written and designed to be clear to the reader". The document also emphasises the importance of a good design that "facilitates navigation and access to information" (2009:7). However, no specific guidelines have been established for the MIL so far.

The MIL, although not a promotional advertisement per se, should be presented in consumer-friendly language; these printed documents have been found to be important in the health field as they complement practitioners' advice and other information resources (the Internet, the nurses, the pharmacist, etc.). Unlike with medicine package leaflets, there is no explicit guidance in the medical field about what is required in the medical informative leaflet or brochure. The MIL should not only be understood as an informative document, but it should also aim at educating patients and to some extent persuading them to change their behavioural healthcare practices and/or ameliorate health problems (Worden \& Flynn, 2001); as such, the design of the document plays an important role in transforming people's understanding of information. Consequently, MILs' effective information design and layout matters, and multimodal attributes such as heading hierarchy, typography, visible structure, colour, visual identifiers, etc. assist readers in understanding and getting the key information.

The communicative and representational scenarios have changed in the last 50 years and visual means of communication are now more prominent, influencing the organisation and presentation of texts, that is, the semiotic landscape (Kress, Leite-García \& van Leeuwen, 1997). Although "writing has always been a multimodal practice" (Archer \& Breurer, 2016:2), it has become more multimodal over the years, now including visual and oral aspects, as well as other multimedia technological advances. The social origins and production of a text become paramount and build the socio-semiotic landscape, 
where attention is given to all forms of meaning (Kress \& van Leeuwen, 1997). This multimodal approach becomes the basis of this study, that is, "to understand all the representational modes which are in play" in the MIL assuming that in social semiotics there is "a motivated relation between signifier and signified" (Kress et al., 1997: 258259).

The inclusion of the MIL in the medical curriculum for university students has proven to be a helpful tool for medical students to draw on semiotic and discursive resources for meaning-making (Weiss, 2014). In her study about multimodality and medicine, Weiss (2014) concludes that by asking students to produce pamphlets or any other health promotion materials within a framework of social semiotics develops patientcentred communication practices useful for the medical professional world. In the study carried out here, the participants are a group of first-year degree medical students enrolled in the English for Healthcare module at a Spanish university who have been asked to create a MIL as part of the output to be assessed in the subject. These medical students are not provided with instructional input on how to develop and design the informative leaflet or brochure. I depart from the assumption that students' knowledge of antecedent genres, similar for example to health promotion materials, generates the necessary connections to develop the multimodal assignment (Jamieson, 1995; Bronwyn, 2016). Their own domestic experience as patients, at some point in their lives, or in the case of other relatives, diseases and visits to health centres provides them with the necessary knowledge to generate the expected content and the use of the genre conventions of the MIL. In the end students manage to negotiate the genres they know and the new genres with confidence and expertise. Eventually, medical students' previous knowledge of this type of genre and their own personal preceding experience 
in the healthcare field may provide those insights needed for the development of the English assignment aiding the affluence of genre conventions.

Multimodal pedagogies can help students in completing multimodal projects in the university classroom as "models of application rather than theoretical insights" (Bezemer \& Jewitt, 2010: 180). Curricular design at university should aim at providing the understanding of discursive practices and genre knowledge of the profession; this is the understanding of the communicative purpose and goal of the genre (Bhatia, 1999; Badger \& White, 2000). In this particular case, the MIL is a well established genre whose aim is to provide patients with information and advice about a particular disease and whether to treat or prevent it.

In the sections that follow, I show how the inclusion of a multimodal genre approach in the medical curriculum can aid medical students to become aware of semiotic choices and design, and prepare them for a socially diverse professional environment where they will have to face different challenges.

\section{The study}

This study aims to analyse multimodality in MILs produced by students of medicine to see how images and other semiotic modes combine with text-flow, adding meaning to the message and broadening the communicative spectrum in what I call here a multimodal genre approach. The focus of this paper are the possible pedagogical implications of applying multimodality to the teaching and learning of languages in the higher education curriculum, proving that multimodality can be "a field of application rather than a theory" (Bezemer \& Jewitt, 2010: 180). 
The study took place in the English for Health Sciences module for first year medical students at a Spanish university. The English for Health Sciences curriculum has been designed following the premises of the Bologna declaration (June 1999) for the creation of the European Higher Education Area (EHEA). The English for Medicine module puts emphasis on the preparation of future doctors for a multicultural and socially diverse environment, which culminates with the practice of the profession in all its different facets (Author et al., 2012). Thus, the outcomes of the module take into consideration the real needs of Medical Practitioners (MPs) as regards the English language. These involve: a) The doctor as a professional-practitioner, b) the doctor as a researcher, and c) the doctor as a lecturer. Concerning the generic and specific competences in the English for Health Sciences module, these are described in Table 1:

\section{Table 1}

Generic and specific competences in the English for Health Sciences module.

- English communication. Knowing English language as a vehicle for medical knowledge dissemination.

- Academic and professional English knowledge and command applied to Medicine.

- The doctor as a lecturer/pedagogue.

- Autonomous learning

The material used in the sessions includes the use of highly specific texts in meaningful contexts which are relevant for the development of the medical students' future professions (Author, 2016). The students are initially provided with six texts dealing with six different health topics or diseases extracted from the World Health Organisation (WHO) site. Each text comes accompanied with a series of questions for 
students to answer; some questions can be directly answered from the text, while others require students' individual research to be answered. The initial topics introduced through the texts are: Text 1: Avian Influenza, Text 2: Leptospirosis in India, Text 3: Obesity and overweight, Text 4: Female Genital Mutilation (FGM), Text 5: Diabetes, Text 6: HIV/AIDS. The questions are relevant to each text and topic. Nevertheless, there are some general questions for every text related to the definition of the health topic or disease, description of symptoms, treatment, prevention, cure (if any), etc. An example of an excerpt from a text and its distinctive questions are illustrated in Table 2.

Table 2

Practical sessions text sample and related questions.

\section{Text \#5: DIABETES}

Key facts

- 346 million people worldwide have diabetes.

- In 2004, an estimated 3.4 million people died from consequences of high blood sugar.

- More than $80 \%$ of diabetes deaths occur in low- and middle-income countries.

- WHO projects that diabetes deaths will double between 2005 and 2030.

- Healthy diet, regular physical activity, maintaining a normal body weight and avoiding tobacco use can prevent or delay the onset of type 2 diabetes.

Diabetes is a chronic disease, which occurs when the pancreas does not produce enough insulin, or when the body cannot effectively use the insulin it produces. This leads to an increased concentration of glucose in the blood (hyperglycaemia). Type 1 diabetes (previously known as insulin-dependent or childhood-onset diabetes) is characterized by a lack of insulin production. Type 2 diabetes (formerly called non-insulin-dependent or adult-onset diabetes) is caused by the body's ineffective use of insulin. It often results from excess body weight and physical inactivity. Gestational diabetes is hyperglycaemia that is first recognized during pregnancy.

Source: WHO site 2004. Available at: http://www.who.int

1. When does diabetes occur?

2. Glucose is a synonym for.....

2. Explain the 2 different types of diabetes

3. Which organs can diabetes affect? (Browse web)

4. Which are the symptoms?

5. Does diabetes occur in high-income countries?

6. Provide a definition of the disease, including diagnosis, treatment, prevention and other relevant 
information.

The students in groups have to choose one of the topics from the initial texts provided or any other current health topic or disease they would like to talk about to prepare a group oral presentation. For this presentation, they must include the development and design of an informative leaflet or brochure about the topic or disease chosen. This assignment is part of the final module assessment and corresponds to $30 \%$ of the final grade. The percentage given to this joint assignment (oral presentation plus informative leaflet) is quite important for the total assessment; it has an equal weight as the final written examination in an attempt to highlight the importance of different means of communication and the combination of different semiotic modes.

Table 3

English for Health Sciences module assessment.

\begin{tabular}{|ll|}
\hline $\begin{array}{l}\text { English for Health Sciences module } \\
\text { ASSESSMENT }\end{array}$ & Percentage \\
\hline Portfolio/Report & $10 \%$ (min. 5\%) \\
Written exam & $30 \%$ (min. 15\%) \\
Oral exam (individual) & $20 \%$ (min. 10\%) \\
Group presentation + leaflet & $30 \%$ (min. 15\%) \\
Problem solving activities & $10 \%$ (min. 5\%) \\
\hline TOTAL (pass) & $\mathbf{1 0 0 \%}$ (min. 50\%) \\
\hline
\end{tabular}

One of the objectives of the English for Health Sciences module, and more concretely of the MIL assignment, is to develop students' sensitivity towards the cognitive structuring of specialist genres. The MIL is analysed here as a multimodal tool for communication where images and other semiotic modes combine with text-flow to create meaning. Through the creation of MILs in the English for Medicine university 
classroom, students learn how meaning can be conveyed in different ways including a full range of semiotic modes (verbal, visual, and oral) used in a particular society (Jewitt \& Kress, 2003).

Using a multimodal genre approach, in this study I analyse a corpus of MILs designed and developed by students of medicine without having any previous classroom instructional knowledge about the genre. MILs are the kind of health informative documents delivered at consultations and hospitals in order to give additional or new information to patients, as well as to instruct and educate them about whether to improve or change some health habits and/or routines, and ameliorate or prevent diseases.

The study departs from the following research questions: a) Which multimodal artefacts do students use to the development and design of MILs? And b) How do multimodal artefacts such as images, figures, tables, diagrams or other graphic elements elaborate the accompanying text for meaning-making?

I observe the text-image relations, MILs page layout, and the use of other visual materials, along with some general considerations regarding text-flow style and use of language. By looking into these features, I intend to demonstrate that the introduction of multimodal assignments in the English for Medicine university curriculum can help students to develop awareness of the semiotic modes as means of meaning-making and communicating, and can also improve medical students' social, academic, and professional skills. By developing multimodal MILs, medical students enhance creativity, generate meaning, and establish meaningful links between signifier and signified through previous popular knowledge of the conventional norms. These aspects 
will allow them to improve their patient-doctor communication environment as well as succeed in their content academic assignments.

\section{Method}

\subsection{The corpus}

As explained in the previous section, creating a MIL is one of the tasks in the English for Health Sciences module included within the assessment of the spoken presentation about a disease or a relevant health issue. The leaflet is used as supporting material and handed out in class when delivering the oral presentation. The general aim of these leaflets is to promote comprehension and information recall in patients; this is more effectively achieved through multimodal representations by combining textual and pictorial elements. Previous studies on multimodal means of communication have proven that humans have a "cognitive preference for picture-based, rather than textbased, information" (Katz, Kripalani \& Weiss, 2006), what some authors have coined as "picture superiority effect". These pictorial preferences are even more helpful in patient education materials, such as the medical informative leaflet analysed in this study, to promote the problem-solving mental model on patient readers (Sansgiry, Cady \& Adamcik, 1997).

To carry out the analysis, I compiled a corpus of 50 MILs designed and developed by first-year medical students enrolled in their English for Health Sciences module. The leaflets were produced over two academic years from 2015-2016 to 2016-2017. The topics chosen by the medical students for their oral presentation and leaflet design corresponded mostly to the six texts provided in the practical sessions in class or from any other current health topic or disease the students were interested in (see Table 2 and 
preceding text). Table 4 shows the corresponding health topics for the 50 MILs analysed in this study: there are twenty different health topics. Issues such as Diabetes, AIDS/HIV, or Female Genital Mutilation (FGM) correspond to the initial texts used in class and have largely been chosen by the students; however, other topics such as Ebola, lung cancer or Alzheimer's disease complete the list according to the students' preferences and current social health concerns and issues, as in the case of the Ebola outbreak in 2015 .

\section{Table 4}

Corpus sample: MILs health topics.

\begin{tabular}{|c|c|c|}
\hline Health topic & \#instances & \% percentage \\
\hline 1.Diabetes & 13 & $26 \%$ \\
\hline 2.AIDS/HIV & 9 & $18 \%$ \\
\hline 3.FGM & 5 & $10 \%$ \\
\hline 4.Obesity \& overweight & 4 & $8 \%$ \\
\hline 5.Malaria & 2 & $4 \%$ \\
\hline 6.Alzheimer's disease & 2 & $4 \%$ \\
\hline 7.Ebola & 2 & $4 \%$ \\
\hline 8.Albinism & 1 & $2 \%$ \\
\hline 9.Hepatitis & 1 & $2 \%$ \\
\hline 10.Skin cancer & 1 & $2 \%$ \\
\hline 11.Autism & 1 & $2 \%$ \\
\hline $\begin{array}{l}\text { 12.Cardio-vascular } \\
\text { diseases }\end{array}$ & 1 & $2 \%$ \\
\hline 13.Cystic fibrosis & 1 & $2 \%$ \\
\hline 14.Huntington's disease & 1 & $2 \%$ \\
\hline 15.Leptosirosis & 1 & $2 \%$ \\
\hline 16.Lung cancer & 1 & $2 \%$ \\
\hline
\end{tabular}




\begin{tabular}{|lll|} 
17.Narcolepsy & 1 & $2 \%$ \\
18.Tuberculosis & 1 & $2 \%$ \\
$\begin{array}{l}\text { 19.Anorexia } \\
\text { nervosa/Eating disorders }\end{array}$ & 1 & $2 \%$ \\
20.Asthma & 1 & $2 \%$ \\
\hline TOTAL & $\mathbf{5 0 ~ M I L s}$ & $\mathbf{1 0 0 \%}$ \\
\hline
\end{tabular}

\subsection{The analysis}

The construct of the MIL genre involves the discourse community, the institution, and the audience consumer. The discourse community is represented by healthcare professionals including MPs, nurses, and auxiliary staff; the institution could be a hospital, a healthcare centre, or consultation, in the private or public sector. Finally, the audience consumer applies to patients in general, whether suffering from an illness or receiving preventive information.

In this particular case, the discourse community for the analysis is represented by medical students learning English language and professional skills for their future employability. The institution is the university, an educational rather than a professional institution, and the audience consumer is not the patient but the other classmates and the module teacher who is going to assess the assignment. However, the process was carried out with maximum care to be as professional as possible as part of the students' training programme.

For the analysis of the MILs, I have taken into consideration how the text-image relations are constituted in terms of multimodality to generate the leaflet page. I have followed Bateman's (2008: 106) view of the page as a "site of integration" in terms of what he calls text-typographic, graphic, and diagrammatic (e.g. vertically or 
horizontally organised page content, page distribution, etc.). This analysis is based on Bateman's Genre and Multimodality model (GeM) and looks for multimodal genre patterns taking into consideration organisation of the page contents and hierarchical relations, appearance and other general considerations on the use of language, and how images in general combine with text-flow (Bateman, 2009).

The students had never created a MIL before either in Spanish or in English. However, they seemed to be familiar with the MIL genre either because they had been provided with one at some point, or because they saw them displayed in health centres and elsewhere, as they commented in class. Therefore, I could also observe how the students' previous domestic and popular knowledge of antecedent genres (Bronwyn, 2016) is applied and implemented to the multimodal and linguistic elaboration of medical assignments such as the informative leaflet in English.

The results obtained from the preliminary analysis of the 50 MILs, including page layout, hierarchy, and other general considerations on language use, provide a qualitative overview of the multimodal features observed.

\section{Results}

The findings presented here are organised according to the analysis of the MIL page layout and the observation of how text-flow is simultaneously combined with images and/or the use of any other visual materials such as diagrams, tables, figures, maps etc. on the basis of the MIL layout. Other aspects such as complexity of language and syntactic structure are also described regarding patient-consumer readability and MIL access, although not the main object of analysis.

\subsection{The MIL page layout}


After observing and analysing the page layout of the 50 informative leaflets, a regular distribution of text and images can be described. Except for three of the 50 leaflets which had the information distributed in a two-side diptych, the rest of the leaflets distributed the layout of the page in the form of a triptych page, that is, the text and the images were displayed in three main differentiated columns distributed in a vertical dimension and presented in three folds. This column distribution can definitely help the potential reader navigate the information while unfolding the triptych. The text in the three vertical columns was 'justified' (aligned left and right) with a clear and homogeneous line space. A high contrast between text-flow and images was observed: white background paper contrasts with the colour text and images, making it clearer and easier to read. All leaflets were printed in colour and with comprehensible hierarchical sections and headings in A4 size paper. Capital letters, bold, and italics typefaces were used to distinguish key information, which was preceded by marked colourful headings at multiple levels when needed, thus facilitating navigation and legibility.

As regards the kind of information found and included in the MILs, I observed that all the leaflets included aspects such as cause of the disease or definition, diagnosis, symptoms, treatment, transmission, or prevention. There were minor variations in some leaflets about infectious diseases that sporadically included a section about epidemiology (disease incidence and prevalence). This choice of contents is not arbitrary; the students could have taken these ideas from the questions included in the initial texts provided in class (see Table 2) or from their own background knowledge on the MIL genre.

The general page layout (outer side) of the 50 MILs analysed when in landscape layout has been sketched in Figure 1. 


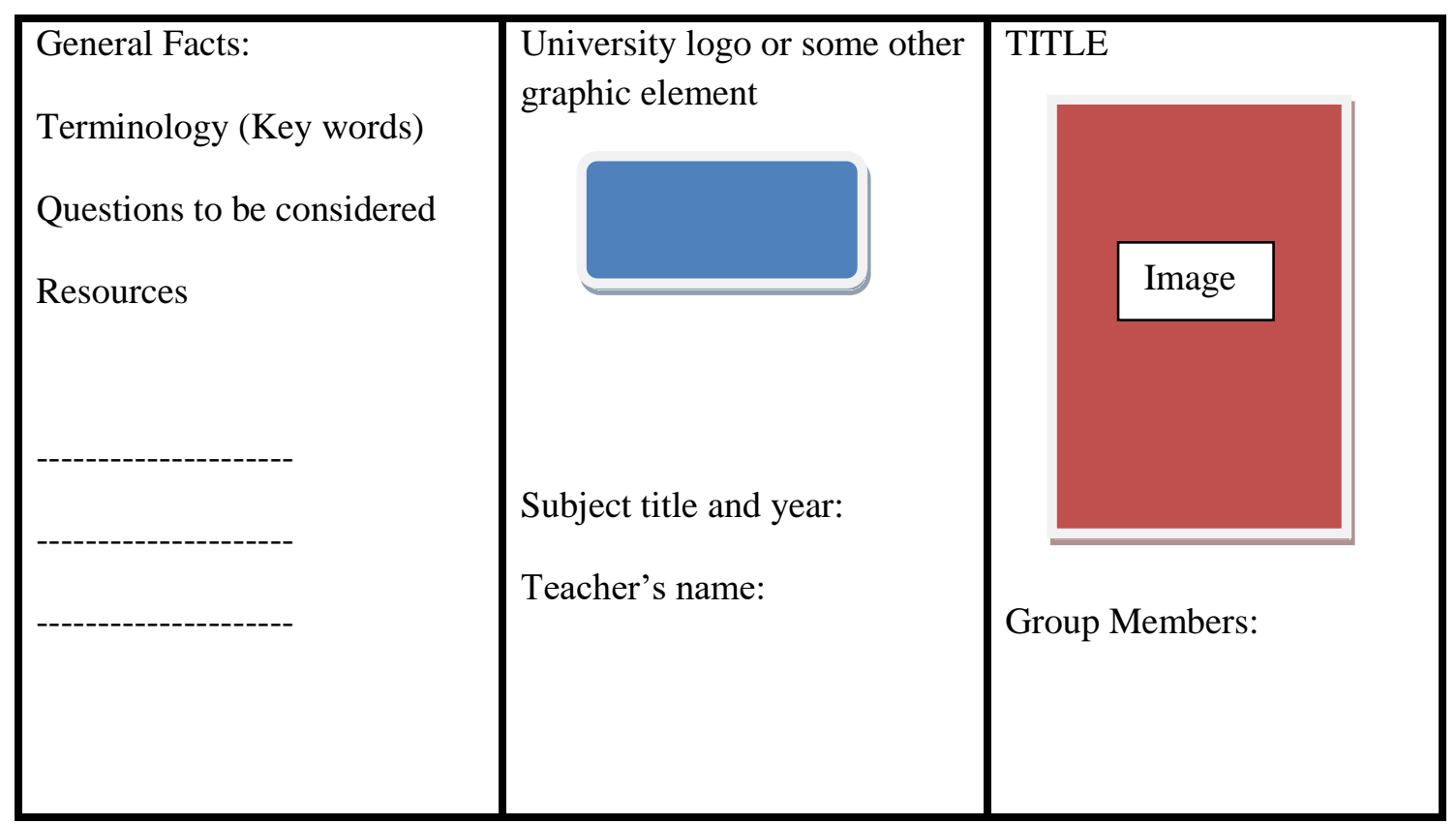

Fig. 1. Outer MIL triptych layout sketch.

As expected, some of the headings, sections, and information provided in the MILs designed by the medical students included aspects that would not be integrated in authentic professional health informative leaflets. Especially in the outer triptych layout (see Figure 1) details such as the subject title and code, the name of the lecturer in charge of the assessment, the names of the people integrating the group who designed the leaflet, or the university institutional logotype are usual. However, taking into consideration that this was an assignment to be assessed and delivered in class, these particular details were expected and they do not affect the MIL meaning-making. An example from a MIL leaflet and the outer triptych layout is shown in Figure 2, data regarding university logotype, proper names, and other personal data have been removed to maintain anonymity. 

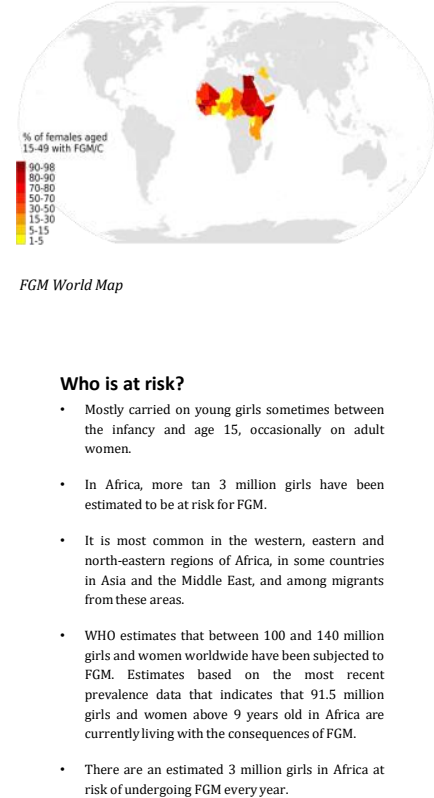

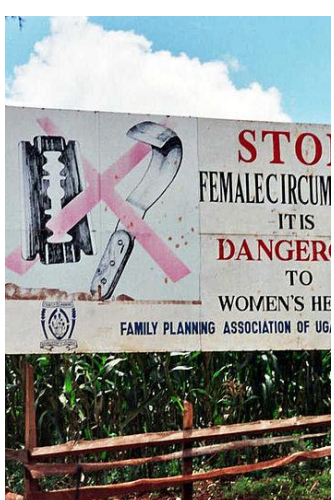

FEMALE

GENITAL

MUTILATION

A procedure performed

especially as a cultural rite

that typically includes the

total or partial excision of the

female external genitalia and

especially the clitoris and

labia minora and that is now

labia minora and that is now
outlawed in many nations

outlawed in many nations
including the United States

Fig. 2. MIL sample, outer layout: FGM.

4.2. The combination of text-flow and images and other visual materials (meaningmaking)

When combining semiotic modes, text-flow mostly combines with images to elaborate or present evidence of the health topic under discussion. In the leaflets analysed, I have tried to make a distinction among different graphic elements, distinguishing among images, diagrams, statistical data, and maps. When referring to images, I intend a plain photo or picture, whereas diagrams in the leaflets analysed make reference to pictorial directions in a sequenced order to give instructional or pedagogical information and advice to the reader. Other types of graphic elements used in the MILs are geographical maps and graphs or charts showing statistical data, especially in health topics related to infectious diseases such as AIDS or Ebola (see examples in Figures 3, 4 and 5). 


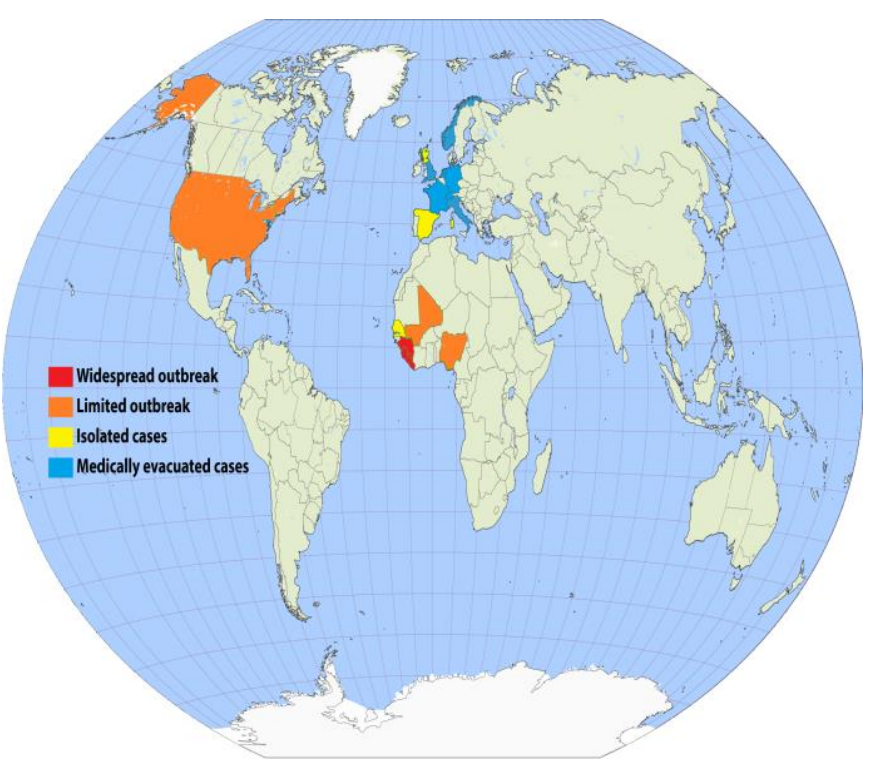

Fig. 3. Ebola outbreak map (from an Ebola leaflet).

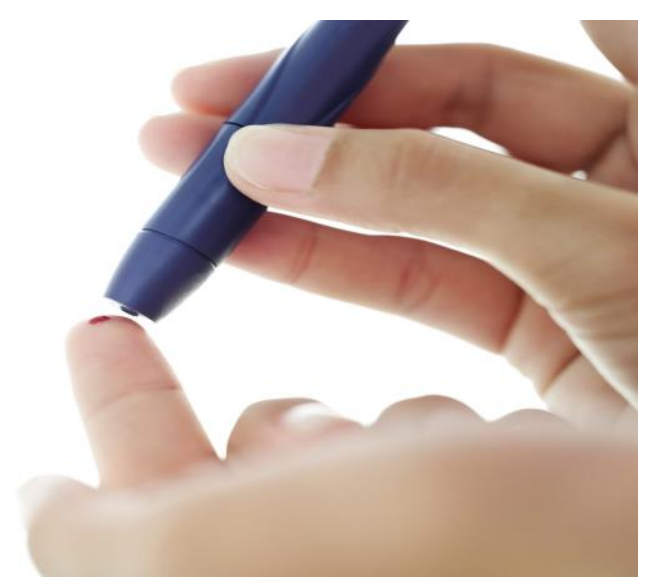

Fig. 4. A photo image from a diabetes leaflet. 


\section{WORLD DIABETES DAY}

As of 2014, around 387 million people worldwide have diabetes. What is the cause of this disease, and what is the difference between the different types? Here, we take a brief look.
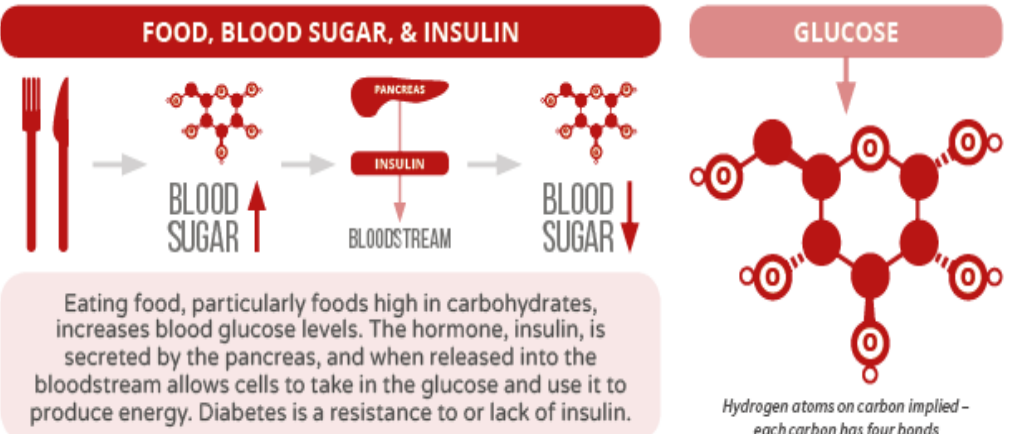

each atorms on carbon implied-

\section{TYPE 1 DIABETES}

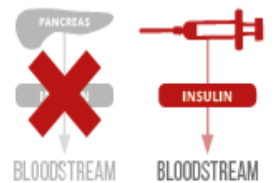

The immune system attacks insulin-producing cells in the pancreas, until it cannot produce insulin, and it must be injected instead.

\section{TYPE 2 DIABETES}

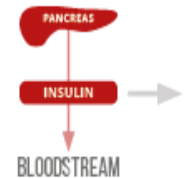

The body becomes resistant to insulin's effects, and its production eventually decreases. Exercise and diet can help manage type 2.
GESTATIONAL DIABETES

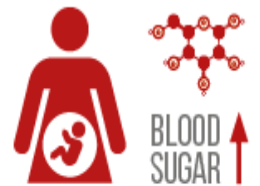

High blood sugar levels can occur during 1 in 25 pregnancies. It usually disappears after childbirth, but can lead to type 2 .

Fig. 5. Diagram with intructional content about diabetes.

The analysis of the 50 leaflets from a multimodal point of view to understand how textflow and images combine and elaborate meaning revealed that the graphic elements referred here as images (photos or pictures) generally are accompanied by text, whereas the diagrams have no additional text explanation apart from their own. The usual distribution of information of the inner triptych is a combination of graphic elements and simple sentence explanations and instructions. When presenting the health topic or disease, a photo image accompanied with text is preferred. To present symptoms and treatment, some variations appear and here photo images or diagrams are common, especially in the symptoms section; when it comes to treatment, the instructional text is 
essential and it is usually combined with pictures. Under the prevention heading photos or diagrams are used, but there is not a major trend towards the use of photos or diagrams in the leaflets analysed. When the leaflet includes information related to epidemiology of a disease, the multimodal mode preferred is geographical maps, graphs and charts showing relevant statistical data, or a combination of both.

A general template of the inner triptych page layout after the analysis of the 50 MILs can be seen in Figure 6.

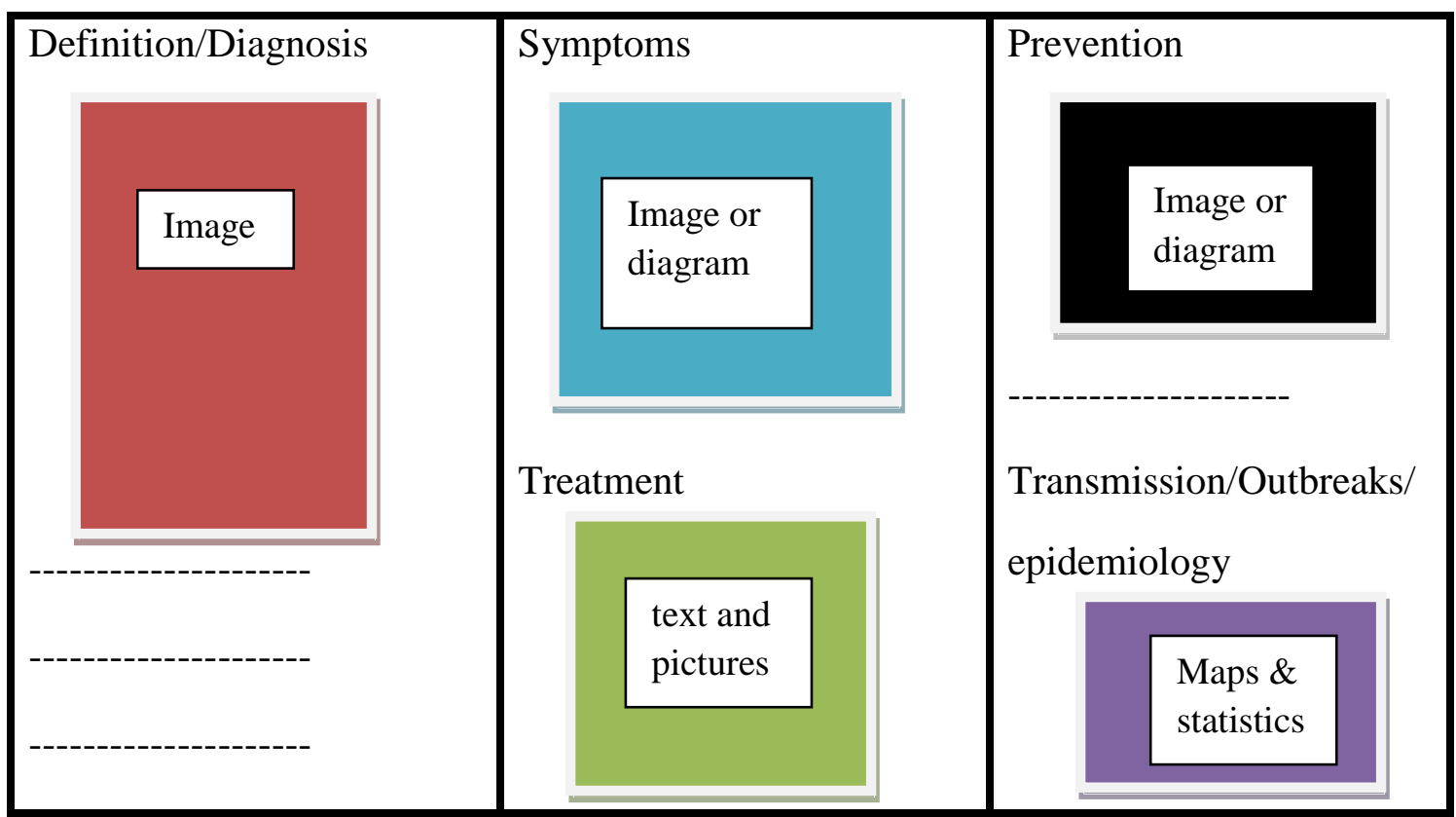

Fig. 6. Inner MIL triptych layout sketch.

\subsection{Language issues}

The MIL is an instructive text, generally with a pedagogical character according to the level of specialisation, style, and register used (Bowker \& Pearson, 2002; Author, 2017). Its general communicative goal is to inform and give advice to ultimately provoke a behavioural change in the reader to improve his/her health habits. To do so, the informative messages have to be expressed clearly and with reader-friendly language to achieve their communicative and persuasive goals. 
The MILs analysed tend to use simple sentences, paragraphs are short, and active voice predominates over passive. Passive voice is mainly used in two clearly recognized structures in the definition/diagnosis section when the cause of the disease is explained, or in the transmission section through structures such as: 'AIDS is caused by a virus $(\ldots)$ ' or 'Ebola is transmitted by (...)'. Except for these specific cases, verbs are used predominantly in the active and imperative forms. Present active voice tends to be used to explain the health topic or disease, as we can read in examples 1 and 2, whereas imperative forms are predominant in the treatment and prevention sections (example 3 ).

(1) Introduction: Narcolepsy is a chronic neurological disorder involving the loss of the brain's ability to regulate sleep-cycles normally. (Narcolepsy \#44)

(2) Definition: Diabetes is a problem that affects lots of people in our world. We can diagnose about 366,000,000 people with diabetes at the moment. Most of these people have diabetes type 2 . We can improve our health doing regular exercise or having a special diet. (Diabetes \#3)

\section{(3) Prevention:}

- Get tested and know your partner's HIV status.

- Have less risky sex, use condoms and limit the number of your sexual partners.

- Don't inject drugs. (AIDS \#7)

The way text-flow is distributed to generate meaning along the page, especially when listing information, is very distinctive. The MILs analysed showed a tendency towards the use of bullets when generating lists (example 3). However, none of the MILs included more than five or six lines or items in the bullet list, perhaps due to a lack of space or to avoid giving too much information to the patient reader to process. This fact coincides with the recommendations of the readability guidance for package leaflets published by the European Commission (2009: 9) that recommends "no more than five or six bullet points in a list". This same readability guidance recommends the avoidance of abbreviations and acronyms in medical package leaflets; however, as I observed in 
the MILs analysed, acronyms and abbreviations are generally used and often needed. As a classroom assignment for the English for Health Sciences module, the students are aware of the difficulties of the medical terminology they are handling. For some of them it is the first time they have encountered this specific terminology and they have to deal with it in English, a language that is not their mother tongue. Therefore, the importance of including glossaries in the informative leaflet is vital for its comprehension. Although not a trait shared in all the leaflets analysed, glossaries have a key role in the MIL as a classroom assignment in a language subject as it is the case here. Figure 7 illustrates an example of a glossary as shown in a Diabetes MIL placed in the inner side of the three triptych columns.

\section{GLOSSARY}

Diabetes: disease caused because the glucose can't be distributed in the body.

Polyuria: When you urine too much. Polyphagia: When your hunger grows too much.

Polydipsia: When you drink too much. Hyperglycaemia: Blood sugar levels are very high.

Oral drugs: The tablets and pills that you take.

Insulin resistance: When the insulin doesn't work in your body.

Fig. 7. An example of glossary from a diabetes leaflet.

When abbreviations or acronyms are essential for the explanation and understanding of the health topic or disease described in the MIL, some students opted to include the list of acronyms and abbreviations as part of the leaflet page layout for clarification (see Figure 8). 


\section{Glossary of Acronyms}

HIV: Human Immunodeficiency Virus

AIDS: Acquired Immunodeficiency Syndrome

STI: Sexually Transmitted Infection

STD: Sexually Transmitted Disease

VD: Venereal Disease

$A R V:$ Antiretroviral

Fig. 8. An example of a list of acronyms included in an AIDS triptych.

\section{Discussion}

In this analysis, I have shown how argumentation is constructed through the realisation of different modes: text-flow, images, and other graphic elements. The academic assignment analysed here comprises different semiotic systems, including written language, images, and visual paralanguage that implicates font and layout. The MIL has proven to be an instructive text with a pedagogical persuasive character since it is used in the medical environment to inform patients and persuade them of healthy habits and good care. By introducing the MIL as a classroom assignment in a higher education institution in a language module, the students have been exposed to the cognitive skills and acquired knowledge of the informative leaflet as a genre (Bhatia, 2012). Moreover, they have made associations with the conventional textual and linguistic features, as well as the social, academic, and professional conventions of such a setting (Osman, 2004).

With reference to the first research question and the type of multimodal artefacts used, the MILs designed and produced by first-year medical students have shown the importance of the combination for semiotic modes (text-flow, images, and other graphic 
elements) in the creation of meaning. Following Bateman's (2008) model, the page layout of the MILs produced by the students revealed a standard distribution of combination of text-flow and multimodal artefacts. In relation to the second question and how meaning is generated through multimodal resources, the medical students demonstrated a broad-based knowledge of concepts related to health topics and diseases such as cause, transmission, prevention, treatment, prevalence, and incidence that have been organised in hierarchical relations. From the analysis of the graphic elements, several main multimodal artefacts have been identified: images or photos, diagrams or pictorial instructions, geographical maps, and graphs or charts for showing statistical data. When a photo is used, it usually combines with some text; on the contrary when a diagram is used no text is added by the students.

As regards language use, the MILs under study are well designed and clearly worded with plain, comprehensible language. The students succeeded in promoting comprehension and information recall in the patients/readers. They seem to be quite aware of the importance of graphic elements combined with text for the creation of meaning in this type of genre; the "picture superiority effect" is paramount in the leaflets observed (Sansgiry et al., 1997). In the case of medication instructions, patients in general seem to prefer the combination of text and pictures for obtaining information as this helps patients' medical information recall and comprehension (Houts, Doak \& Doak, 2006; Morrow et al., 2004). In the MIL genre, the choice of language used in terms of syntax, tenses, style, and terminology plays an important role; patient readers can be varied and diverse: elderly people, low-literacy groups, patients with some visual impairment or even with limited language proficiency in the case of a foreign language. 
The MILs analysed generally used simple sentences, short paragraphs, and active voice over passive to ease navigating and maximise access to information.

Overall, although not identical in organisation of the page contents or in the amount and type of visual material used, the MILs produced by the students follow the general standards of the genre (Bhatia, 2004) according to page layout organisation and language choices; thus achieving the intention and social purpose of the MIL. The assignment gave the students the opportunity to practice and learn about the semiotic and discursive resources in academic and professional domains for meaning-making.

When evaluating the amount of previous knowledge medical students have about health information genres and its influence on the development and design of a MIL as a classroom assignment, the findings show that the students seemed to use their knowledge of antecedent genres - concretely the MIL genre, in completing the multimodal project. This is because they had not been asked before to produce such an assignment in their medical curriculum at university and elsewhere, as they indicated in class. They appeared to negotiate the antecedent knowledge of the genre of MIL with expertise to produce their own MILs with the help of technological advances such as Internet and image handling software. The combination of images and text-flow could be successfully fulfilled thanks to students' digital skills using specific software for image storage and manipulation as well as automatic triptych software generators. These digital skills were not taught in class; in fact, they were part of the technological knowledge students previously had. The medical students participating in this study not only managed to portray the conventions of the genre without receiving any instructional input about it, but they also gained knowledge of the English language and the specificity of the field. Asking students to generate their own multimodal texts 
allows them to use language that makes sense to them and that they can remember more easily in the future for their medical profession.

The present findings offer an interesting reflection on how university students' resources (previous genre convention knowledge, meaning making abilities, technological skills, textual interpretation, and instructional strategies) are validated in an academic educational context to provide access to medical professional discourses for their future professional development. As future MPs, the students will probably have to generate their own devices to instruct, persuade, and be able to communicate with patients, other colleagues and/or medical students in the diagnosis, treatment, prognosis, and research of a disease or health topic. Hopefully, this study will serve as an example of research on the process of 'conscious design' within a framework of multimodal genre approach in the medical curriculum.

\section{Conclusion}

The aim of this paper was to analyse multimodality in the genre of medical leaflets and discuss the opportunities and advantages of introducing multimodal assignments in the English for Medicine classroom at university. The assignment here was to produce and design MILs of health topics and diseases discussed in class without receiving any instructional input about the conventions of the genre in order to prompt students' creativity and to avoid possible homogeneity and equity of MILs through intrusive instructions.

The inclusion of a multimodal genre approach in the university curricular design has been shown to be beneficial for students' academic and professional skills learning and practice. The multimodal genre approach for the teaching of English in specific contexts 
may benefit graduate students in the professional world by enhancing communication, understanding, and meaning making in a multiculturally diverse environment. The students will become more aware of the actions and artefacts used in the communicative spectrum. These multimodal teaching practices can support students in their global learning process and have positive effects on learning a language and the specific terminology of the field. They can also highlight the production of meaning rather than the acquisition of received input. However, the effectiveness of these multimodal practices needs new pedagogies to develop awareness of different semiotic choices (Archer, 2016) and tools for multimodal assessment. The MILs created by medical students here served to evaluate the students' oral competences by presenting the MILs in class. Aspects such as MILs spatial distribution, visual choices, information organisation, clarity, and performance should be taken into consideration when evaluating students. This type of assessment should go far beyond the evaluation of linguistic accuracy issues and represents an example of a more multimodal assessment (visual and aural) in relation to the English language and genre knowledge. For a multimodal assessment to be successful, tools such as the design of broader evaluation rubrics, which include the assessment of semiotic modes, and the use and knowledge of technological means for handling visual and aural production, seem necessary.

\section{References}

Author. (2012).

Author. (2016).

Author. (2017).

Archer, A., \& Breurer, E. O. (2016). Multimodality in Higher Education. Studies in writing series, Vol. 33. Leiden, Boston: BRILL, (Chapter 1). 
Archer, A. (2016). Multimodal academic argument: ways of organising knowledge across writing and image. In A. Archer, \& E.O. Breurer (Eds.), Multimodality in Higher Education. Studies in writing series (pp. 93-112). Leiden, Boston: BRILL.

Badger, R., \& White, G. (2000). A process genre approach to teaching writing. ELT Journal 54(2), 153-160.

Bateman, J. A. (2008). Multimodality and genre: a foundation of the systematic analysis of multimodal documents. London: Palgrave Macmillan, (Chapter 3).

Bateman, J. A. (2009). Discourse across semiotic modes. In J. Renkema (Ed.), Discourse, of course: an overview of research in discourse studies (pp. 55-66). Amsterdam and Philadephia: Benjamins.

Bhatia, V. K. (1999). Disciplinary variations in business English. In M. Hewings, \& C. Nickerson (Eds.), Business English: research into practice. London: Longman.

Bhatia, V. K. (2004). Worlds of written discourse. New York: Continuum, (Chapter 5).

Bhatia, V. K. (2012). Critical reflections on genre analysis. Ibérica, 24, 17-28.

Bezemer, J. \& Jewitt, C. (2010). Multimodal analysis: key issues. In L. Litosseliti (Ed.), Research methods in linguistics, (pp.180-197). London: Continumm.

Bowker, L., \& Pearson, J. (2002). Working with specialized language. London: Routledge, (Chapter 2).

Bronwyn, T. W. (2016) Genre inside/genre outside: how university students approach composing multimodal texts. In A. Archer, \& E.O. Breurer (Eds.), Multimodality in Higher Education. Studies in writing series (pp. 114-135). Leiden, Boston: BRILL.

Buendía, M., \& Ureña, J. M. (2010). ¿Cómo diseñar un corpus de calidad? Parámetros de evaluación. Sendebar, 21, 165-180.

DeLorme, D. E., Huh, J., Reid, L. N., \& An, S. (2007).The state of public research on over-the-counter drug advertising. International Journal of Pharmaceutical and Healthcare Marketing, 4 (3), 208-231.

Dickinson, D., Teather, J., Gallina, S., \& Newsom-Davis, E. (2010). Medicine package leaflets - does good design matter? Information Design Journal, 18(3), 225-240.

European Commission (2009). Guidelines on the readability of the labelling and package leaflet of medical products for human use. Revision 1. Brussels, European Commission. http://ec.europa.eu/health/sites/health/files/files/eudralex/vol2/c/2009_01_12_readability_guideline_final_en.pdf Accessed 03/06/2017. 
Houts, P. S., Doak, C.C., \& Doak, L.G. (2006). The role of pictures in improving health communication: a review of research on attention, comprehension, recall and adherence. Patient Education and Counselling, 61, 173-190.

Jamieson, K. M. (1975). Antecedent genre as rhetorical constrain. Quarterly Journal of Speech, 61, 406-415.

Jewitt, C. \& Kress, G. (2003) Multimodal literacy. New York: Peter Lang, (Chapter 2).

Katz, M. G., Kripalani, S., \& Weiss, B. D. (2006). Use of pictorial aids in medication instructions: A review of literature. American Journal of Health-System Pharmacy, 63(1), 2391-2397.

Kress, G., Leite-García, R., \& van Leeuwen, T. (1997). Discourse semiotics. In T.A. van Dijk (Ed.), Discourse as structure and process. Discourse studies: a multidisciplinary introduction (pp. 257-291). London, Thousand Oaks, New Delhi: SAGE Publications.

Kress, G. \& van Leeuwen, T. (1997). The Multi-modal text. London: Edward Arnold, (Chapter 2).

Morrow, D., Weiner, M., Deer, M., et al. (2004). Patient-centred instructions for medications prescribed for the treatment of heart failure. The American Journal of Geriatric Pharmacotherapy, 2, 44-52.

Osman, H. (2004). Genre-based instruction for ESP. The English Teacher, 33: 13-29.

Sansgiry, S.S., Cady, P. S., \& Adamcik, B. A. (1997). Consumer comprehension of information on over-the-counter medication labels: effects of picture superiority and individual differences based in age. Journal of Pharmaceutical Marketing and Management, 11, 63-76.

Vita Bianco, A. (2015). Informa(c)tion. How to do things with medicine information leaflets. Lingue e Linguaggi, 15, 27-52.

Weiss, R. (2014). Multimodality and medicine. Designing for social futures. In A. Archer, \& D. Newsfield, (Eds.) Multimodal approaches to research and pedagogy. Recognition, resources and access (pp. 153-173). New York and London: Routledge.

Worden, J. K., \& Flynn, B. S. (2001). The case for persuasive health messages. Effective Clinical Practice, 4(2), 73-75. 